\title{
Received Oil Yields and Chemical Compounds of Mixed Grass Synthesized by Pyrolysis Process
}

\author{
Kittiphop Promdee ${ }^{1,2}$, Tharapong Vitidsant ${ }^{3}$ \\ ${ }^{1}$ Inter-Department of Environmental Science, Chulalongkorn University, Bangkok 10330, Thailand. \\ ${ }^{2}$ Department of Environmental Science, Chulachomklao Royal Military Academy, Nakorn Nayork, 26001, \\ Thailand. \\ ${ }^{3}$ Department of Chemical Technology, Chulalongkorn University, Bangkok 10330, Thailand.
}

\begin{abstract}
The pyrolysis of mixed grass (Cogongrass and Manilagrass), conducted criteria with temperatures in the range of $400-500^{\circ} \mathrm{C}$, the feeding rate of 150,350 , and $\left.550 \mathrm{rpm}\left(\mathrm{r} \cdot \mathrm{min}^{-1}\right)\right]$. Preliminary result of proximate analysis was founded that the high volatile matter, low ash and moisture. The products yield calculation showed that the liquid yield of bio-oil obtained from mixed grass was highest of $42.37 \%$ at 350 rpm, the gases and the solid yield of mixed grass by during pyrolysis were 28.88 and $28.75 \%$, at 350 rpm, respectively,. Indicated that biomass from mixed grass had good received yields because of low solid yield and gas yield and high liquid yield at $350 \mathrm{rpm}$. The compounds detected in bio-oil from mixed grass showed that the functional groups, especially; Phenols (24.78\%), Phenol, 2,3-dimethyl-(2.52\%), Phenol, 2,6dimethoxy (14.48\%), Phenol, 2-methoxy-(3.18\%), Phenol, 3-methyl-(3.23\%), Phenol, 2-methyl-(4.97 \%), Phenol, 4-ethyl-2-methoxy-(3.95\%), alcohols, and ketones.

Keywords:Continuous Pyrolysis, Product Yields, Chemical Compound, Cogongrass, Manilagrass.
\end{abstract}

\section{Introduction}

Biomasses are organic materials composed of carbon, oxygen, hydrogen, nitrogen and other trace elements. The potential energy compounds usually found in biomass are cellulose, hemicellulose and lignin. This research was conducted by using two grasses (Cogongrass; Imperata cylindrical (L.)P.Beauv. and Manilagrass; Zoysia matrella (L.)Merr.) transformed to bio-oil by continuous pyrolysis reactor on standard criteria and analysis the properties of material and products. In present, the fuel is being concerned in every country [1-3]. Now we are looking at the fuel which synthesized from natural matter, especially; residual plant $[5,6]$ by using the pyrolysis method (Fig 1).

Continuous pyrolysis reactor is a one excellent of technology for synthesized bio-oil [7-9]. In this case want to produce bio-oil in high potential performance of yield and properties by applied the heat transfer model for control some criteria of reactor to an generate the alternative energy source. This study focuses on the conversion of two grasses, a natural weed, into bio-oil using pyrolysis. The product yields is then calculated and the obtained bio-oil is analysed for its composition.

\section{Materials And Methods}

\section{1) Feedstock and Experimental Set-up}

The mixed grass sample is chopped and crushed before being placed in an oven at $90{ }^{\circ} \mathrm{C}$ for approximately 2 hours until the moisture content is below $5 \%$. The sample is then passed through a sieve to obtain particle sizes of approximately $0.1-1 \mathrm{~mm}$. It is then fed into continuous reactor (Fig. 2), for pyrolysis at the following operating conditions: operating temperature $400-500^{\circ} \mathrm{C}, \mathrm{N}_{2}$ flow rate $150 \mathrm{ml} / \mathrm{hr}$, and sample screw feeder at 150,350 and $550 \mathrm{rpm}\left(\mathrm{r} \cdot \mathrm{min}^{-1}\right)$. The bio-oil product was analysed by Ultimate analyser and Proximate analyser for characteristics and elemental composition before calculating the received oil yields. Further analysis of the chemical compounds found in the bio-oil product was carried out using Gas Chromatography with Mass Spectrometer. 


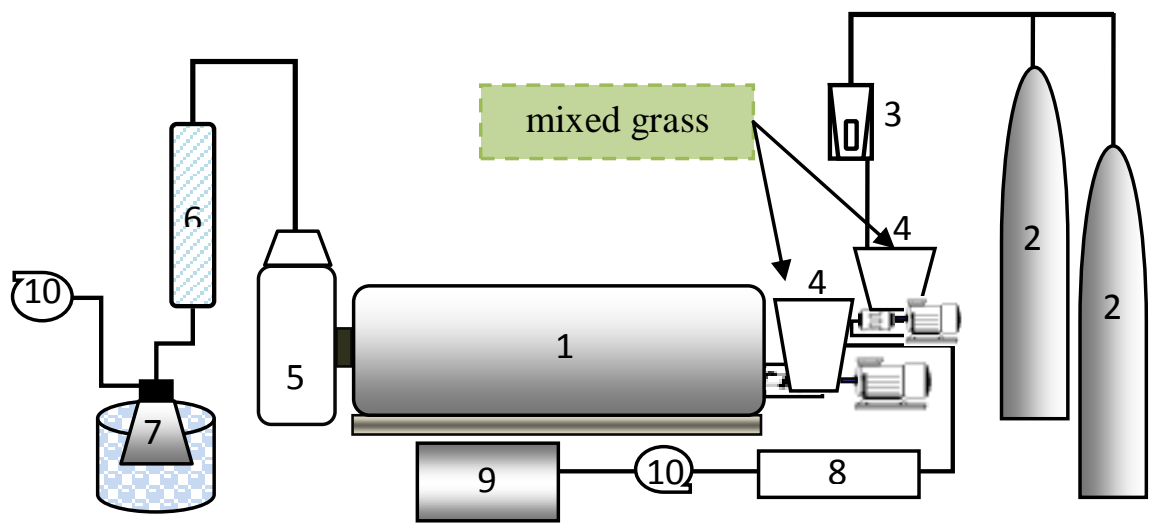

Fig. 1. Schematic diagram of experiment setup: 1. Pyrolysis reactor (tube furnace) 2. Nitrogen tank 3 . Rotameter 4. Hopper 1,25. Seperator 6. Condenser7. Flask in ice bucket8. Electrical coil heater with temperature controller 9. Enclosed deionized water tank 10. Vacuum pump

\section{2) Proximate Analysis}

Proximate analysis is the most used analysis for characterizing biomass in connection with their utilization; separating the products into 4 groups: (1) moisture, (2) volatile matter, (3) fixed carbon, and (4) ash. A series of standard test methods ATSM D3173-3175 are executed and the calculated test results show the distribution of products obtained when the sample is heated under specified conditions.

\section{3) Ultimate Analysis}

In this experiment, the Ultimate Analysis was used to identify the proportions of Carbon (C), Hydrogen $(\mathrm{H})$, and Nitrogen $(\mathrm{N})$ elements found in the bio-oil sample [10,11].

\section{4) Received Oil Yield}

$$
\begin{array}{ccc}
\% \text { Liquid yield } & =100 \times\left[\frac{W_{\text {Liq }}}{W_{\text {ini }}}\right] \\
\% \text { Solid yield } & =100 \times\left[\frac{W_{R}}{W_{\text {ini }}}\right] \\
\% \text { Gas yield } & =100-\% \text { Liquid yield }-\% \text { Solid yield } \\
\mathrm{W}_{\text {ini }} & = & \text { Initial weight } \\
\mathrm{W}_{\mathrm{R}} & = & \text { Residual solid weight } \\
\mathrm{W}_{\mathrm{Liq}} & = & \text { Liquid product weight }
\end{array}
$$

\section{5) Chemical analysis}

Gas Chromatography with Mass Spectrometer, GC-MS was used to analyze the light components in bio-oil and investigating the molecular compositions qualitatively $[12,13]$. The analysis detects and identifies organic compounds both aliphatic hydrocarbon and aromatic hydrocarbon found within the light components of the produced bio-oil.

\section{Results And Discussions}

Proximate analysis of mixed grass used in the two species was founded that the fixed carbon of mixed grass was 18.78 wt.\%, which will have a major effect on the quality of bio-oil as well. The other three proximate analysis as following; The moisture, ash and volatiles of mixed grass were 2.26, 16.34 and 62.62 wt.\%, respectively (Table. 1 ).

The results showed that a stability for the range of material compound in mixed grass, can be synthesized bio-oil in high efficiency, because consist of the high volatile matter and low ash and moisture.

The ultimate analysis of mixed grass was found that the element contents as following; carbon, hydrogen, nitrogen and oxygen were 47.45, 10.57, 2.87 and $38.76 \%$, respectively (Table. 1)., according to the result of safflower seed [13] showed the carbon, hydrogen, nitrogen, and oxygen of 49.5 , $6.9,3.0$, and 40.6 , respectively. 
Table 2. Proximate analyses and Ultimate analyses of mixed grass.

\begin{tabular}{|c|c|c|c|}
\hline Proximate analysis & $\begin{array}{c}\text { Mixed grass } \\
(\mathrm{wt} \%)\end{array}$ & Ultimate analysis & $\begin{array}{c}\text { Mixed grass } \\
(\mathrm{wt} \%)\end{array}$ \\
\hline Moisture & 2.26 & $\mathrm{C}$ & 47.45 \\
\hline Ash & 16.34 & $\mathrm{H}$ & 10.57 \\
\hline Volatiles & 62.62 & $\mathrm{~N}$ & 2.87 \\
\hline Fixed carbon & 18.78 & $\mathrm{O}$ & 38.76 \\
\hline
\end{tabular}

The result of products yield (3-phase; gas, liquid and solid) of mixed grass by during pyrolysis, which takes place at temperatures in the range of $400-500^{\circ} \mathrm{C}$, to compare the recicved oil yield from mixed grass at a feed rate of feed rate of 150, 350 and $550 \mathrm{rpm}$; revolutions per minute $\left.\left(\mathrm{r} \cdot \mathrm{min}^{-1}\right)\right]$. The distribution of the products obtained from the pyrolysis of mixed grass is shown in Figure 2-4.

Preliminary calculate of the product yield of mixed grass by during pyrolysis, the result showed that the gas yield of mixed grass were 24.98, 28.88 and $46.14 \%$, at 150, 350 and 550 rpm., respectively., (Fig. 2).

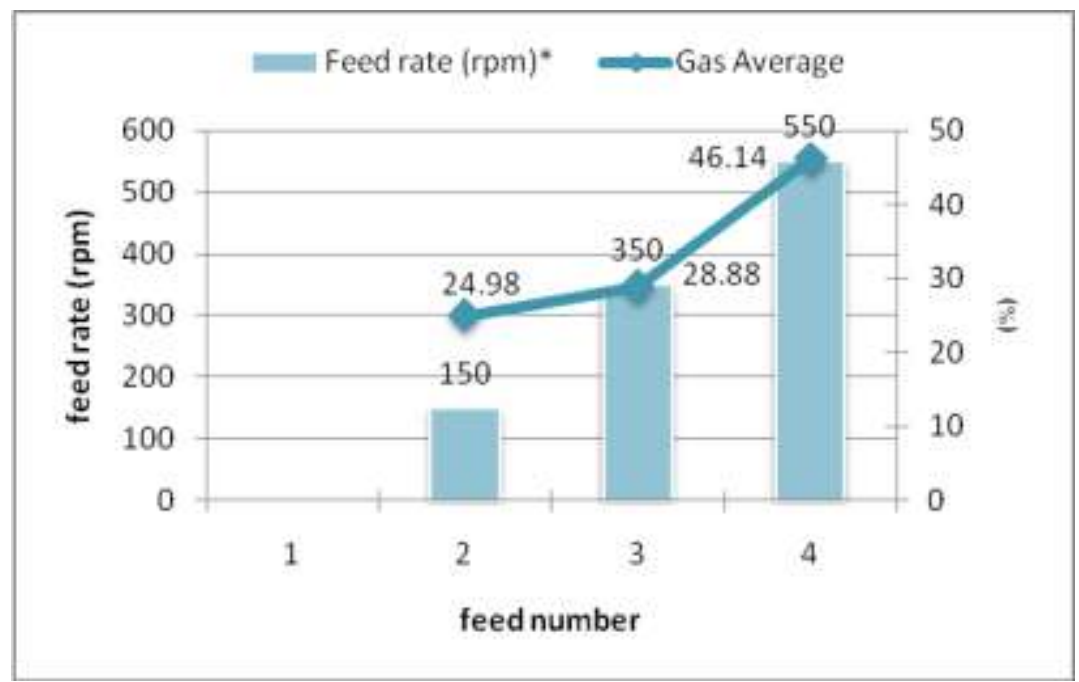

Fig. 2 Gas yield of mixed grass by during pyrolysis.

Liquid yield of bio-oil obtained from mixed grass was highest of $42.37 \%$, at $350 \mathrm{rpm}$. And the another of liquid yield obtained from mixed grass were 28.25 and $29.38 \%$, at 150 and $550 \mathrm{rpm}$., respectively (Fig. 3). Indicated that the liquid yield of bio-oil obtained from mixed grass was high volume (>50\%) by the heat control in continuous pyrolysis reactor and can be improving to high efficiency of bio-oil production on next step.

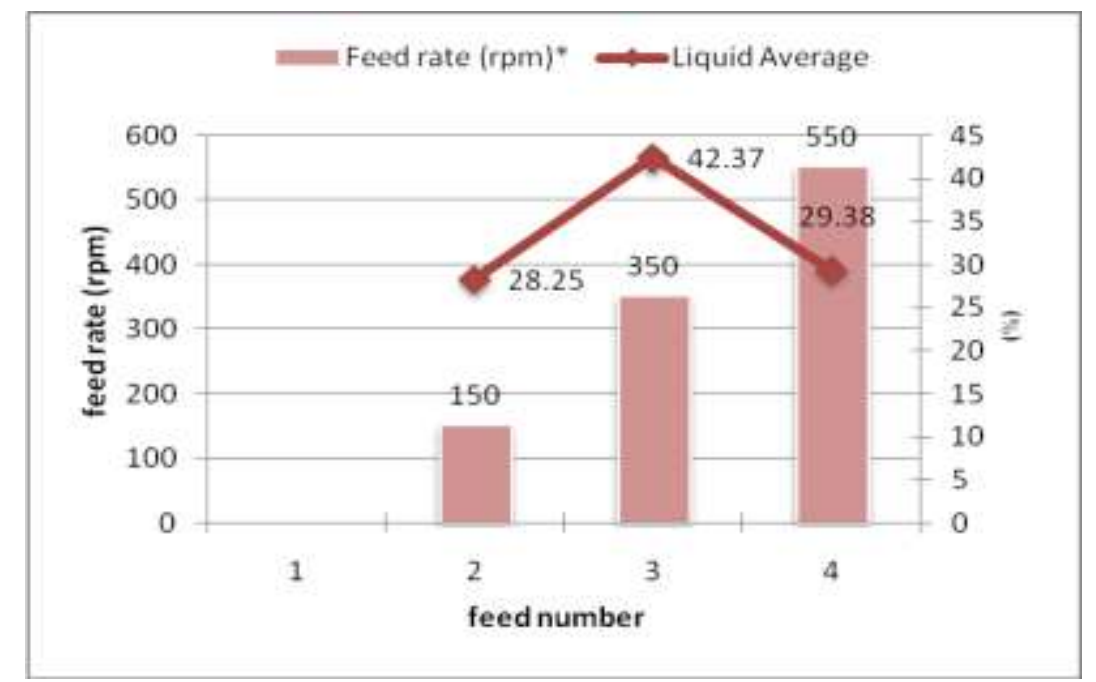

Fig. 3Liquid yield of bio-oil obtained from mixed grass. 


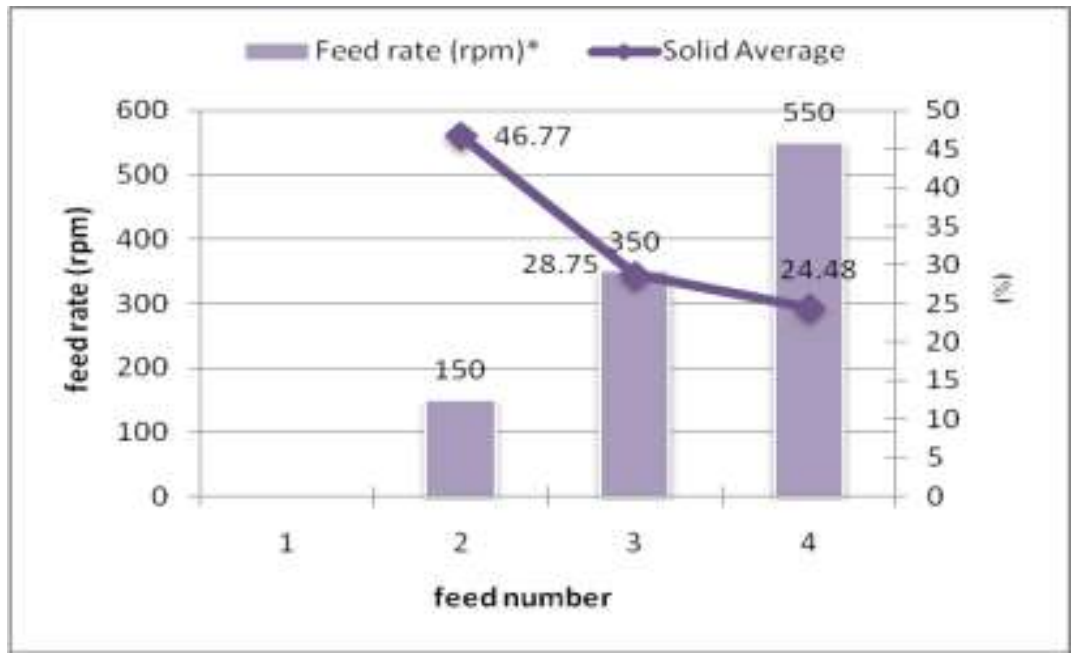

Fig. 4 Solid yield of mixed grass by during pyrolysis.

Solid yield of mixed grass by during pyrolysis was highest of $46.77 \%$, at $150 \mathrm{rpm}$. And the another of solid yield obtained from mixed grass were 28.75 and $24.48 \%$, at 350 and 550 rpm., respectively (Fig. 4).

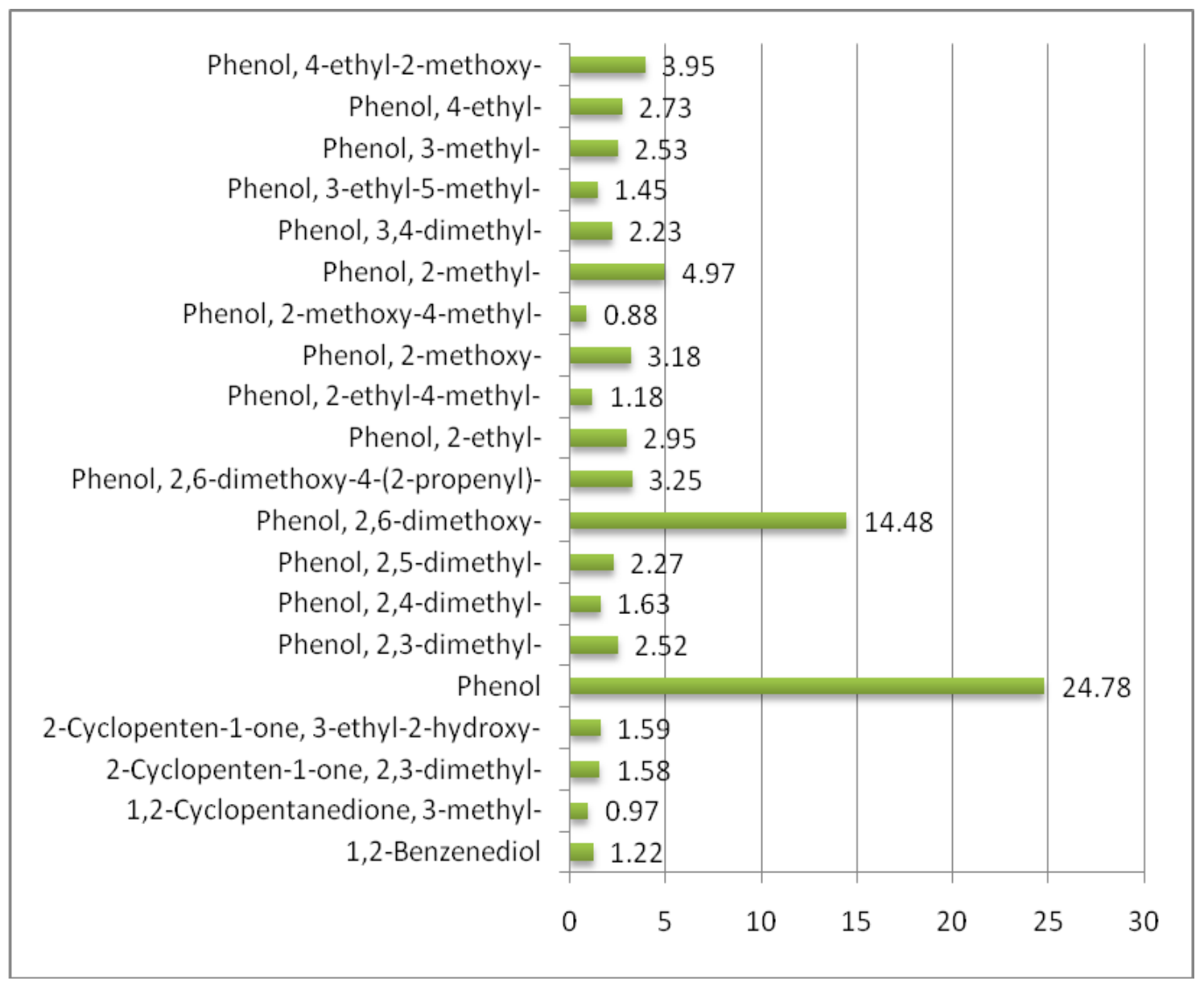

Fig. 5 The amount of some molecule compounds of bio-oil obtained from mixed grass.

The compounds detected in bio-oil from mixed grass showed that the hydrocarbon compounds composed of hydroxyl and carboxyl groups, including; Phenols (24.78 \%), Phenol, 2,3-dimethyl-(2.52\%), Phenol, 2,6-dimethoxy (14.48 \%) ,Phenol, 2-methoxy-(3.18\%), Phenol, 3-methyl-(3.23\%), Phenol, 2-methyl(4.97\%), Phenol, 4-ethyl-2-methoxy-(3.95\%), alcohols, and ketones. These chemical compounds showed in investigating the molecular compositions in Fig 2., detecting compounds of bio-oil from several biomass $[14,15]$. However; the compounds detected in bio-oil from mixed grass as similar results were reported by the 
topics; Formation of aromatic structures during the pyrolysis of bio-oil [14] and Selective production of light oil by biomass pyrolysis with feedstock-mediated recycling of heavy oil [15]. These results show agreement between proposed model and experimental data of the several biomass pyrolysis.

Table 2. Compounds detected in bio-oil from mixed grass

\begin{tabular}{|c|c|c|c|c|}
\hline Compound & formula & MW & Detection & Molecules \\
\hline $\begin{array}{l}\text { Benzene, 1-ethyl-4- } \\
\text { methoxy- }\end{array}$ & $\mathrm{C}_{9} \mathrm{H}_{12} \mathrm{O}$ & 136 & $*$ & \\
\hline $\begin{array}{l}\text { 1,2-Cyclopentanedione, } 3 \text { - } \\
\text { methyl- }\end{array}$ & $\mathrm{C}_{6} \mathrm{H}_{8} \mathrm{O}_{2}$ & 112.12 & $x$ & \\
\hline $\begin{array}{l}\text { 2-Cyclopenten-1-one, 2,3- } \\
\text { dimethyl- }\end{array}$ & $\mathrm{C}_{7} \mathrm{H}_{10} \mathrm{O}$ & 110 & $x$ & \\
\hline Phenol & $\mathrm{C}_{6} \mathrm{H}_{6} \mathrm{O}$ & 94.11 & $x$ & \\
\hline Phenol, 2,3-dimethyl- & $\mathrm{C}_{8} \mathrm{H}_{10} \mathrm{O}$ & 122.16 & $x$ & \\
\hline Phenol, 2,4-dimethyl- & $\mathrm{C}_{8} \mathrm{H}_{10} \mathrm{O}$ & 122.16 & $x$ & \\
\hline Phenol, 2,5-dimethyl- & $\mathrm{C}_{8} \mathrm{H}_{10} \mathrm{O}$ & 122.16 & $x$ & \\
\hline Phenol, 2,6-dimethoxy- & $\mathrm{C}_{8} \mathrm{H}_{10} \mathrm{O}$ & 122.16 & $x$ & \\
\hline Phenol, 2,6-dimethyl- & $\mathrm{C}_{8} \mathrm{H}_{10} \mathrm{O}$ & 122.16 & $x$ & \\
\hline Phenol, 2-ethyl- & $\mathrm{C}_{8} \mathrm{H}_{10} \mathrm{O}$ & 122.16 & $x$ & \\
\hline Phenol, 2-methoxy- & $\mathrm{C}_{7} \mathrm{H}_{8} \mathrm{O} 2$ & 124 & $x$ & \\
\hline $\begin{array}{l}\text { Phenol,2-methoxy-4-(1- } \\
\text { propenyl)-, (E)- }\end{array}$ & $\mathrm{C}_{12} \mathrm{H}_{14} \mathrm{O}_{3}$ & 206.23 & $x$ & \\
\hline Phenol, 2-methyl- & $\mathrm{C}_{7} \mathrm{H}_{8} \mathrm{O}$ & 108.13 & $x$ & \\
\hline Phenol, 3,4-dimethyl- & $\mathrm{C}_{8} \mathrm{H}_{10} \mathrm{O}$ & 122.16 & $x$ & \\
\hline Phenol, 3-methyl- & $\mathrm{C}_{7} \mathrm{H}_{8} \mathrm{O}$ & 108.13 & $x$ & \\
\hline
\end{tabular}


Table 2. Compounds detected in bio-oil from mixed grass (Cont'd)

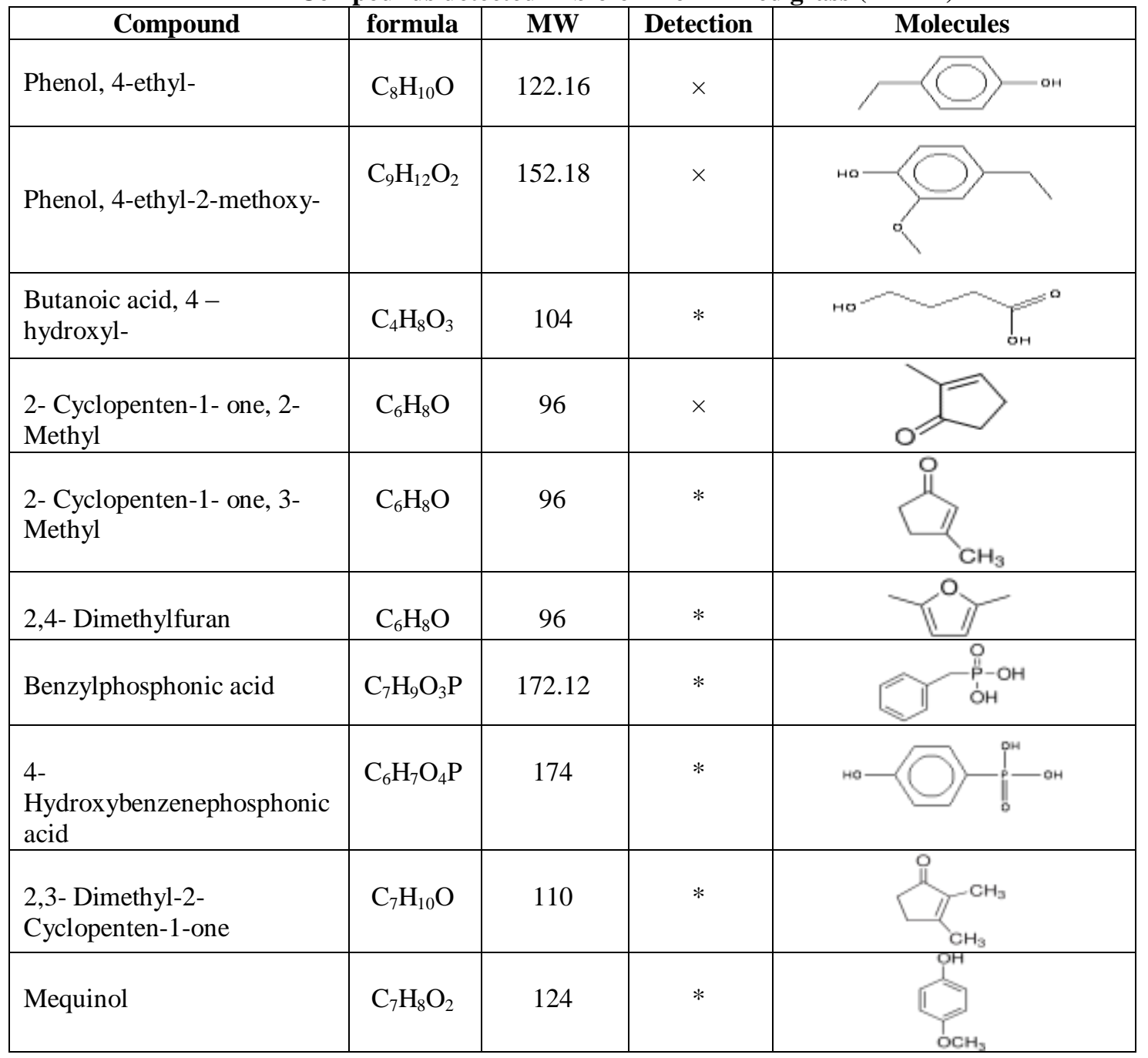

*can not determined

\section{Conclusions}

The continuous pyrolysis reactor of mixed grass presented a high volatiles content and showed a moderate level of fixed carbon. The amount of the elemental composition of mixed grass, can found the concentration of carbon was relatively high volume. The products oil yield showed that liquid yield of bio-oil obtained from mixed grass was a good result was $42.37 \%$, at $350 \mathrm{rpm}$. The compounds detected in bio-oil from mixed grass can found the phenols, alcohols, and ketones, especially; phenols group.

\section{Acknowledgment}

This work was supported by the Higher Education Research Promotion and National Research University Project of Thailand, Office of the Higher Education Commission (EN272A), Ratchadaphiseksomphot Endowment Fund (CU-CLUSTER-FUND), the Thai Government Stimulus Package 2 (TKK2555) under the Project for Promotion of bio and biomass utilization potential for fuel production and exporting technology, and Chulalongkorn University and Research Program on Materials for Future Energy, Center of Excellence on Petrochemical and Materials Technology. 


\section{References}

[1] M. Patel, M. Neelis, D. Gielen, J. Olivier, T. Simmons, and J., Theunis, "Carbon dioxide emissions from non-energy use of fossil fuels: Summary of key issues and conclusions from the country analyses," Resources, Conservation and Recycling , 45 (3), 2005 , 195-209.

[2] M. Garcia-Perez, J. Shen, X. S., Wang, and C-Z Li, "Production and fuel properties of fast pyrolysis oil/bio-diesel blends," Fuel Processing Technology, 91 (3), 2010, 296-305.

[3] G. Duman, C. Okutucu, S. Ucar, R. Stahl, and J., anik, "The slow and fast pyrolysis of cherry seed," Bioresource Technology, 102 (2), 2011,1869-1878.

[4] D. Wu, S. Zhang, J. Xu and T., Zhu, "The $\mathrm{CO}_{2}$ Reduction Effects and Climate Benefit of Beijing 2008 Summer Olympics Green Practice," Energy Procedia, 5 (1), 2011, 280-296.

[5] Q. Lu, W-Z. Li, and X-F., Zhu, "Overview of fuel properties of biomass fast pyrolysis oils," Energy Conversion and Management, 50, 2009,1376-1383.

[6] H. Li, Q. Xu, H. Xue, and Y., Yan. 2009, "Catalytic reforming of the aqueous phase derived from fast-pyrolysis of biomass," Renewable Energy, 36, 2009,1-6.

[7] H.S. Heo, H.J. Park, J-H. Yim, J.M. Sohn, J.H. Park, S-S. Kim, C.K. Ryu, J-K. Jeon, and Y-K., Park. "Influence of operation variables on fast pyrolysis of Miscanthus sinensis var. purpurascens," Bioresource Technology, 101 (10), $2010,3672-3677$.

[8] K. Promdee, T. Vitidsant, and S. Vanpetch. "Comparative study of some physical and chemical properties of bio-oil from Manila grass and Water hyacinth transformed by pyrolysis process”, International Journal of Chemical Engineering and Applications, . 3 (1), 2012, 72-75.

[9] U. Jena, and K. C. Das. "Comparative evaluation of thermochemical liquefaction and pyrolysis for bio-oil production from microalgae. Energy \& fuels, 25, 2011, 5472-5482.

[10] S. Sevgi, and D., Angin, "Pyrolysis of safflower (Charthamus tintorius L.) seed press cake: Part 1. The effect of pyrolysis parameters on the product yields," Bioresource Technology, 99, 2008, 5492-5497.

[11] S. Sevgi, and D., Angin, "Pyrolysis of safflower (Charthamus tintorius L.) seed press cake in a fixed-bed reactor: Part 2. Structural characterization of pyrolysis bio-oils," Bioresource Technology, 99, 2008, 5498-5504.

[12] M. P. Robbins, G. Evans, J. Valentine, I.S. Donnison and G.G. Allison. New opportunities for the exploitation of energy crops by thermochemical conversion in Northern Europe and the UK . Progress in energy and combustion science, 38, 2012, $138-155$.

[13] S. Bilgen, S. Keles and K. Kaygusuz. Calculation of higher and lower heating values and chemical exergy values of liquid products obtained from pyrolysis of hazelnut cupulae. Energy 2012, pp. 1-6.

[14] Y. Wang, X. Li, D. Mourant, R. Gunawan, S. Zhang, and C-Z. Li. Formation of aromatic structures during the pyrolysis of bio-oil. Energy \& Fuels, 26, 2012, 241-247.

[15] Y. Huang, S Kudo, K. Norinaga, M. Amaike, and J-I Hayashi. Selective production of light oil by biomass pyrolysis with feedstock-mediated recycling of heavy oil. Energy \& Fuels. 26, 2012, 256-264. 